\title{
Hemşirelik ve Ebelik Öğrencilerinin Genetik Danışmanlık Rolleri ile İlgili Görüşleri
}

\author{
Sevil Özkan®, Fatma Taş Arslan®
}

Selçuk Üniversitesi Hemşirelik Fakültesi, Hemşirelik Bölümü, Çocuk Sağlığı ve Hastalıkları Hemşireliği Anabilim Dalı, Konya, Türkiye

Sevil Özkan, Arş. Gör. Fatma Taş Arslan, Prof. Dr.

Illetişim:

Arş. Gör. Sevil Özkan

Selçuk Üniversitesi Hemşirelik Fakültesi, Hemşirelik Bölümü, Çocuk Sağlığı ve Hastalıkları Hemşireliği Anabilim Dalı, Konya, Türkiye

Tel: +903322233546

E-Posta: nursevilozkan@gmail.com

Gönderilme Tarihi : 25 Temmuz 2017

Revizyon Tarihi : 25 Eylül 2017

Kabul Tarihi : : 30 Eylül 2017
ÖZET

Amaç: Hemşirelik ve ebelik öğrencilerinin genetik danışmanlık rolleri ile ilgili görüşlerinin belirlenmesidir.

Gereç ve Yöntem: Tanımlayıı tipte çalı̧̧ma, Mart-Nisan 2013 tarihleri arasında bir sağlık bilimleri fakültesinin toplam 130 hemşirelik ve ebelik son sınıf öğrencisiyle yapıldı. Veriler literatüre dayalı oluşturulan yedi soruluk anket formu aracilığılla toplandı. Anket formunda yer alan ilk dört soru öğrencilerin sosyodemografik ve eğitim özelliklerini (yaşı, cinsiyeti, okuduğu bölüm, genetik konusunda alınan eğitimi yeterli bulma durumu) tanımlamaya yönelikti. Diğer üç soru ise genetik danışmanılık sürecindeki mesleki rol ve sorumluluklar ile genetik hastalıkların sosyal etkileri hakkındaydı. Verilerin analizi bilgisayar ortamında yapıldı ve ortalama, sayı ve yüzdeden yararlanıldı.

Bulgular: Öğrencilerin çoğunluğu genetik ile ilgili aldıkları eğitimin yeterli olmadığını bildirdi. Öğrenciler hemşirelerin genetik danışmanlık rollerini çoğunlukla "genetik teste bireyi hazırlama", "bireyin geçmiş sağlık öyküsünü alma", "genetik testlerden önce birey ve aileye gerekli konularda danışmanlık yapma" ve "aileye psikolojik destek sağlama" şeklinde ifade etti. "Aileye psikolojik destek sağlama", "genetik testlerin ve danışmanlık sürecinin sosyal etkileri ile ilgilenme", "genetik test sırasında birey ve aileye gerekli danıșmanlığı yapma" ve "soy ağacı çizme" ise ebelerin genetik rolleri arasında en sık belirtilenlerdi. "Genetik alanında uzmanlaşma", "genetik test sonuçlarılla ilgilenme", "genetik testler ve danışmanlık süreciyle ilgili araştırmalar yapma" ise her iki mesleğinde genetik danışmanlık rolleri arasında oldukça az oranda ifade edildi.

Sonuç: Genetik danıșmanlık ile ilgili verilen eğitimlerin içeriği mesleğe özgü rol ve sorumluluklar doğrultusunda geliştirilmeli, bu süreçte yer alan güncel uygulamalar öğrencilere öğretilmelidir.

Anahtar sözcükler: Ebe, genetik danışmanlık, hemşire.

\section{NURSING AND MIDWIFERY STUDENTS' OPINIONS ABOUT THEIR ROLES IN GENETIC COUNSELING}

\section{ABSTRACT}

Aim: To identify nursing and midwifery students' opinions about their roles in genetic counseling.

Materials and Methods: This descriptive study was carried out between March-April 2013 with total of 130 final year nursing and midwifery students in a health sciences faculty. Data were collected through a seven-item questionnaire which was developed according to literature. The first four questions of the questionnaire were aimed to determine socio-demographic and educational characteristics of the students (age, gender, department, genetics, adequate education). The other three questions were related to professional roles and responsibilities of the genetic counseling process with the social effects of genetic diseases. Data were analysed via a computer and the mean. Numbers and percentages were used in the analysis.

Results: The majority of students reported that education about genetics was not sufficient. Students mostly stated nurses' roles in genetic counselling as "preparing the patientfor the genetic test", "taking the patient's medical history", "counselling the patient and his/her family members before the genetic tests", and "supporting the family psychologically". Most frequently stated genetic roles for midwives were "supporting the family psychologically", "dealing with the social effects of genetic testing and counseling", "counseling the patient and his/her family members during genetic tests" and "drawing pedigree". "' 'Specialization in the field of genetics", "dealing with genetic test results" and "conducting research on genetic testing and counseling procedures" were mentioned sparsely as roles in genetic counseling for both professions.

Conclusion: The contents of genetic counseling related to education should be developed according to the occupational roles and responsibilities. Furthermore, the current practices should be taught to the students in this process.

Keywords: Midwife, genetic counseling, nurse. 
enetik danışmanlık; genetik özelliği olan bir hastalıkla ilgili olarak birey ve sağlık personeli arasında gerçekleşen hastalığın kalıtım şekli, önlenmesi, korunma veya tedavi yollarıla ilgili bilgi verme, psikolojik ve sosyolojik destek sağlama boyutlarını içeren bir iletişim şeklidir $(1,2)$. Geçmiş yıllarda kromozomal anomali ya da genetik mutasyona sahip birey ve ailesine yönelik verilen genetik danışmanlık hizmetleri (3), şeker hastalığı, kanser, kalp hastalığı gibi genel hastalıkların genetik ile ilişkisinin belirlenmesi, genetik testlerin duyarlılığının artması gibi değişimlere bağlı olarak daha geniş alanlarda verilebilmektedir (3-6).

Genetik danışmanlık sürecinin ailede birden fazla kuşağı ilgilendirmesi, hastalıkların doğum öncesi dönemde ya da klinik belirti vermeden önce tanılanması gibi durumlar genetik danışmanlığın özel bilgi ve beceri isteyen bir hizmet dalı olmasına yol açtı $(1,5,7)$. İngiltere, Amerika, İsrail, Japonya gibi farklı ülkelerde 1960'lı yılların sonlarına doğru fark edilen bu gerçek, genetik danışmanlık hizmetine önem vermesine ve konuyla ilgili uzmanların yetiştirilmesini sağladı. Danışmanlık hizmetlerinde doktor, ebe, hemşire, psikolog, genetik danışmanlar gibi birçok farklı sağlık profesyoneli aktif rol aldı (5,7-9).

Ülkemizde ve dünyada genetik danışmanlık sürecinde çoğunlukla doktorlar sorumludur. Literatürde doktor dışındaki sağlık profesyonellerinin konuyla ilgili rol ve sorumluluklarının net olmaması ve ilgili sağlık profesyonellerinin kendilerinin de süreçte aktif görevlerinin olmadığına inanmaları, kurumsal ve bireysel olarak danışmanlık hizmetlerinde doktorlara talebin daha fazla olması hakkında bilgiler vardır. Ancak genetik danışmanlık için başvuran birey ve ailesi ile sürekli iletişim halinde olan ebe ve hemşireler, genetik danışmanlıkta etkin rol almalıdır (1). Barnoy ve arkadaşlarının (8) yaptığı çalışmada uzman doktor ve uzman hemşirenin verdiği genetik danışmanlık hizmetinin topluma aynı derecede güven verdiği bulunmuştur. Literatürde genetik risk faktörlerini tanılama, birey ve aileyi değerlendirme, detaylı aile öyküsü alma, genetik bilgi ve danışmanlık hizmeti sunma, ilgili raporları kayıt altında tutma gibi görevlerin ebe ve hemşireler tarafından yapılabileceği bildirilmektedir $(10,11)$. Ebelik ve hemşirelik eğitiminde genetik ile ilgili müfredatın lisans eğitiminde yer alması bu süreçte önemlidir (12).

Ülkemizde genetik alanında ebelik ve hemşirelik üzerinde yapılmış sınırlı sayıda araştırma bulunmakta olup, mevcut çalışmalar ise genellikle tek bir meslek grubunun mesleki genetik bilgileri, genetik rolleri ve sorumluluklarına odaklı tanımlayıcı niteliktedir (13-15). Dolayısıyla diğer meslek gruplarının birbirlerinin genetik rolleriyle ilgili görüşlerine yönelik çalışmalara gereksinim vardır.

Bu çalışmada, bir sağlık bilimleri fakültesinin ebelik ve hemşirelik öğrencilerinin genetik danışmanlık sürecindeki mesleki rol ve sorumlulukları ile genetik süreçlerin sosyal etkileri hakkındaki görüşlerinin belirlenmesi amacıyla yapıldı.

\section{Araştırma soruları}

1. Ebelik ve hemşirelik öğrencilerinin, ebe ve hemşirenin genetik danışmanlık sürecindeki rol ve sorumlulukları ile ilgili görüşleri nelerdir?

2. Ebelik ve hemşirelik öğrencilerinin, genetik süreçlerin sosyal etkileri ile ilgili görüşleri nelerdir?

\section{Gereç ve yöntem}

Tanımlayıcı tipte olan çalışma, Mart 2013-Nisan 2013 tarihleri arasında Konya ilinde yer alan bir üniversitenin sağlık bilimleri fakültesine devam eden ebelik ve hemşirelik bölümü öğrencileri ile yapıldı. Ebelik ve hemşirelik öğrencilerin genetik ile ilgili konu müfredatını lisans eğitimlerinde ilk üç yıl içinde tamamladıkları belirlendiğinden evrene sadece dördüncü sınıf öğrencileri dâhil edildi. Ebelik bölümünden 97, hemşirelik bölümünden 104 olmak üzere toplamda 201 öğrenci çalışmanın evrenini oluşturdu. Evrenin ulaşılabilirliği dikkate alınarak örneklem seçimine gidilmedi, 70 ebelik ve 60 hemşirelik son sınıf öğrencisi olmak üzere toplam 130 (\%65) öğrenci çalışma grubunu oluşturdu. Ebelik bölümünden 27 , hemşirelik bölümünden 44 öğrenci olmak üzere toplamda 71 öğrenci çalışmaya katılmayı kabul etmedi.

Veriler literatüre dayalı $(7,10,14,16,17)$ oluşturulan yedi soruluk anket formu aracılığıyla toplandı. Anket formunun ilk dört sorusu öğrencilerin sosyodemografik ve eğitim özelliklerine (yaşı, cinsiyeti, okuduğu bölüm, genetik konusunda alınan eğitimi yeterli bulma durumu) yönelikti. Anket formunda yer alan diğer üç soru ise genetik danışmanlık sürecindeki mesleki rol ve sorumluluklar ve genetik hastalıkların sosyal etkileri hakkındaydı. Genetik danışmanlık sürecindeki mesleki rol ve sorumluluklar 15 farklı ifade (genetik alanında uzmanlaşma, soy ağacı çizme, aile öyküsü alma gibi) ile belirtildi, bu görevlerin ebe ve hemşireye ait olma durumu öğrencilere soruldu. Genetik hastalıkların sosyal etkileri ile ilgili olarak öğrencilere 9 farklı ifade ile (ailedeki rol ve sorumluluklar, kardeşler ile ilişki 
vb.) bu konu hakkındaki görüşleri incelendi. Son soruda ise genetik test sonuçları hakkında bilgi verilmesi gereken kişi ve kurumlar incelendi.

Çalışma öncesi yazılı etik kurul izni, Selçuk Üniversitesi Sağlık Bilimleri Fakültesi Girişimsel Olmayan Klinik Araştırmalar Etik Kurulu'ndan 27.03.2013 tarih ve 34967403 sayılı etik kurul kararı ile alınmıştır. Çalışmanın yapıldığı kurumdan yazılı izin alındı. Çalışmanın amacı, önemi ve bilgilerin gizliliği hakkında gerekli bilgiler öğrencilere verildikten sonra, çalışmaya katılmayı kabul eden öğrencilerden sözel izin alındı. Anket formu sınıf ortamında öğrencilerin dersine girmeyen bir başka bölümün öğretim elemanı tarafında öğrencilere uygulandı. Form 15 dakikalık zaman diliminde dolduruldu. Veriler bilgisayar ortamında, sayı, yüzde, ortalama ve standart sapma ile değerlendirildi.

\section{Bulgular}

Araştırmaya katılan öğrencilerin $\% 53,8^{\prime} \mathrm{i}$ ebelik ve $\% 46,2$ 'si hemşirelik bölümü öğrencisiydi ve öğrencilerin \%92,3'ünü kızlar oluşturmaktaydı. Öğrencilerin yaş ortalaması 22,49 $\pm 0,84$ yıl olarak saptandı. Öğrencilerin \%16,2'si devam ettikleri bölümlerde verilen genetik eğitiminin yeterli olduğunu belirtti.

Genetik danışmanlık süreciyle ilgili verilen rol ve sorumlulukların ebe ve hemşireye ait olma durumları hakkında öğrencilerin görüşleri soruldu. Hemşirenin rol ve sorumlulukları arasında en fazla ifade edilenler "genetik teste bireyi hazırlama $(\% 67,7)$, bireyin geçmiş sağlık öyküsünü alma $(\% 60,0)$, genetik testlerden önce aileye gerekli konularda danışmanlık yapma $(\% 60,0)$ ve aileye psikolojik destek sağlamaydı $(\% 60,0) "$. Genetik test sonuçları ile ilgilenme $(\% 15,4)$, genetik alanında uzmanlaşma $(\% 26,9)$, genetik testler ve danışmanlık süreciyle ilgili araştırmalar yapma $(\% 28,5)$ ise hemşirenin rol ve sorumlulukları arasında en az ifade edilenlerdi. Ebelerin rol ve sorumlulukları arasında en fazla ifade edilenler "aileye psikolojik destek sağlama $(\% 41,5)$, genetik test ve danışmanlık sürecinin sosyal etkileri ile ilgilenme $(\% 40,0)$, soy ağacı çizme $(\% 39,2)$, genetik test sırasında birey ve aileye gerekli danışmanlığı yapmaydı $(\% 39,2)$ ". Genetik test sonuçlarıyla ilgilenme $(\% 10,8)$, genetik alanında uzmanlaşma $(\% 20,8)$, aydınlatılmış onam alma (\%23,8), genetik danışmanlık sonrasında gerekli ise başvuran bireyi ilgili uzman bireylere yönlendirme $(\% 23,8)$ ise ebelerin rol ve sorumlulukları arasında en az ifade edilenlerdi (Tablo 1).
Tablo 1. Genetik danışmanlık sürecinde hemşire ve ebenin rol ve sorumlulukları hakkında öğrenci görüşleri $(n=130)$.

\begin{tabular}{|c|c|c|c|c|}
\hline \multirow[t]{2}{*}{ Durum } & \multicolumn{2}{|c|}{ Ebe } & \multicolumn{2}{|c|}{ Hemşire } \\
\hline & $n$ & $\%$ & $n$ & $\%$ \\
\hline \multicolumn{5}{|l|}{ Genetik danışmanlıkta aktif rol alma } \\
\hline - Görevi Değil & 81 & 62,3 & 63 & 48,5 \\
\hline \multicolumn{5}{|l|}{ Genetik alanında uzmanlaşma } \\
\hline - Görevi Değil & 103 & 79,2 & 95 & 73,1 \\
\hline \multicolumn{5}{|l|}{$\begin{array}{l}\text { Genetik testler ve danışmanlık } \\
\text { süreci ile ilgili arastırmalar yapma }\end{array}$} \\
\hline - Görevi Değil & 103 & 79,2 & 93 & 71,5 \\
\hline \multicolumn{5}{|l|}{$\begin{array}{l}\text { Genetik testlerin yararlarını, } \\
\text { sınırlııklarını ve olası risklerini bilme }\end{array}$} \\
\hline - Görevi & 46 & 35,4 & 63 & 48,5 \\
\hline - Görevi Değil & 84 & 64,6 & 67 & 51,5 \\
\hline \multicolumn{5}{|l|}{ Genetik test sonuçları ile ilgilenme } \\
\hline - Görevi Değil & 116 & 89,2 & 110 & 84,6 \\
\hline \multicolumn{5}{|l|}{ Aydınlatılmış onam alma } \\
\hline - Görevi & 31 & 23,8 & 51 & 39,2 \\
\hline - Görevi Değil & 99 & 76,2 & 79 & 60,8 \\
\hline \multicolumn{5}{|l|}{ Bireyin geçmiş sağlık öyküsünü alma } \\
\hline - Görevi Değil & 80 & 61,5 & 52 & 40,0 \\
\hline \multicolumn{5}{|l|}{ Soy ağacı çizme } \\
\hline - Görevi Değil & 79 & 60,8 & 68 & 52,3 \\
\hline \multicolumn{5}{|l|}{ Genetik teste bireyi hazırlama } \\
\hline - Görevi Değil & 80 & 61,5 & 42 & 32,3 \\
\hline \multicolumn{5}{|l|}{$\begin{array}{l}\text { Genetik testlerden önce aileye gerekli } \\
\text { konularda danışmanlık yapma }\end{array}$} \\
\hline - Görevi & 50 & 38,5 & 78 & 60,0 \\
\hline - Görevi Değil & 80 & 61,5 & 52 & 40,0 \\
\hline \multicolumn{5}{|l|}{$\begin{array}{l}\text { Genetik test sırasında birey ve aileye } \\
\text { gerekli danışmanlığı yapma }\end{array}$} \\
\hline - Görevi & 51 & 39,2 & 76 & 58,5 \\
\hline - Görevi Değil & 79 & 60,8 & 54 & 41,5 \\
\hline \multicolumn{5}{|l|}{$\begin{array}{l}\text { Genetik test sonrası danışmanlık } \\
\text { yapma }\end{array}$} \\
\hline - Görevi & 47 & 36,2 & 67 & 51,5 \\
\hline - Görevi Değil & 83 & 63,8 & 63 & 48,5 \\
\hline \multicolumn{5}{|l|}{$\begin{array}{l}\text { Başvuran bireyi genetik danışmanlık } \\
\text { sonrasında gerekli ise konu ile ilgili } \\
\text { uzman bireylere yönlendirme }\end{array}$} \\
\hline - Görevi & 31 & 23,8 & 52 & 40,0 \\
\hline - Görevi Değil & 99 & 76,2 & 78 & 60,0 \\
\hline \multicolumn{5}{|l|}{ Aileye psikolojik destek sağlama } \\
\hline - Görevi & 54 & 41,5 & 78 & 60,0 \\
\hline - Görevi Değil & 76 & 58,5 & 52 & 40,0 \\
\hline \multicolumn{5}{|l|}{$\begin{array}{l}\text { Genetik testlerin ve danışmanlık } \\
\text { sürecinin sosyal etkileri ile ilgilenme }\end{array}$} \\
\hline - Görevi & 52 & 40,0 & 76 & 58,5 \\
\hline - Görevi Değil & 78 & 60,0 & 54 & 41,5 \\
\hline
\end{tabular}


Araştırmada genetik hastalık ve danışmanlık sürecinin bireyin sosyal yaşamına etkileri hakkında öğrenci görüşleri incelendiğinde, öğrenciler "bireyin aile içindeki rol ve sorumluluklarını $(\% 92,3)$, çocuk sahibi olma kararlarını $(\% 91,5)$, geleceğe yönelik planlarını $(\% 90,8)$ " etkilediğini ifade etti. Bireyin eşi ile ilişkisi $(\% 89,2)$, çalışma hayatı $(\% 86,9)$, çocuk ve ebeveynleri ile ilişkisi $(\% 83,8)$ de öğrenciler tarafından etkilendiği ifade edilen diğer durumlar arasındaydı (Tablo 2).

Tablo 2. Genetik hastalıklar ve danışmanlık sürecinin bireyin sosyal yaşamına etkileri hakkında öğrenci görüşleri $(n=130)$.

\begin{tabular}{lcccc} 
Görüşler & \multicolumn{3}{c}{ Etkileme Durumu } \\
\hline & \multicolumn{2}{c}{ Var } & \multicolumn{2}{c}{ Yok } \\
\hline Ailedeki rol ve sorumluluklar & 120 & 92,3 & 10 & 7,7 \\
Eş ile ilişki & 116 & 89,2 & 14 & 10,8 \\
Çocuk veya ebeveynlerle ilişki & 109 & 83,8 & 21 & 16,2 \\
Kardeşler ile ilişki & 96 & 73,9 & 34 & 26,2 \\
Akrabalar ile ilişki & 91 & 70,0 & 39 & 30,0 \\
Çocuk sahibi olma kararı & 119 & 91,5 & 11 & 8,5 \\
Gelecek ile ilgili planlar yapma & 118 & 90,8 & 12 & 9,2 \\
Arkadaşlarıyla olan ilişki & 94 & 72,3 & 36 & 27,7 \\
Çalışma hayatı & 113 & 86,9 & 17 & 13,1
\end{tabular}

Araştırmada genetik test sonuçları hakkında bilgi verilmesi gereken kişi ve kurumlar ile ilgili öğrenci görüşleri incelendiğinde; öğrencilerin tamamı "genetik danışmanlık için başvuran bireye" bilgi verilmesi gerektiğini ifade ederken; diğer bilgi verilmesi gereken kişi ve kurumlar ise doktor $(\% 96,9)$, hemşire $(\% 93,1)$, ebe $(\% 92,3)$, birinci derece yakınları $(\% 90,8)$, okulu $(\% 51,5)$ ve işvereni $(\% 48,46)$ ifade edildi (Tablo 3).

Tablo 3. Genetik test sonuçları hakkında bilgi verilmesi gereken kişi ve kurumlar ile ilgili öğrenci görüşleri $(n=130)$.

\begin{tabular}{lcccc}
$\begin{array}{l}\text { Kişi ve } \\
\text { kurumlar }\end{array}$ & $\begin{array}{c}\text { Bilgi } \\
\text { verilmeli }\end{array}$ & \multicolumn{3}{c}{$\begin{array}{c}\text { Bilgi } \\
\text { verilmemeli }\end{array}$} \\
\hline & $\boldsymbol{n}$ & $\%$ & $\boldsymbol{n}$ & $\%$ \\
\hline Başvuran birey & 130 & 100 & - & - \\
Birinci derece yakını & 118 & 90,8 & 12 & 9,2 \\
Doktor & 126 & 96,9 & 4 & 3,1 \\
Hemşire & 121 & 93,1 & 9 & 6,9 \\
Ebe & 120 & 92,3 & 10 & 7,7 \\
İşveren & 63 & 48,5 & 67 & 51,5 \\
Okul & 67 & 51,55 & 63 & 48,45
\end{tabular}

\section{Tartışma}

Insan Genom Projesi ile hız kazanan genetik alanındaki gelişmeler, hastalıklardan korunma, hastalıkların erken tanılanması ve tedavisi süreçlerinde yeniliklere yol açmıştır. Yaşanan bu gelişmeler, mevcut sağlık hizmetlerinin sunumunun yeniden incelenmesine ve genetik konusunda alanına özgü mesleki bilgi ve beceriye sahip sağlık personelinin varlığına olan ihtiyacı arttırmıştır. Başta doktorlar, hemşireler ve ebelere olmak üzere tüm sağlık personeline bazı rol ve sorumluluklar yüklenmiştir $(4,7,14)$.

Genetik danışmanlık süreci bireyin sağlık kurumuna başvurması ile başlamakta olup bireyin ihtiyaç duyduğu danışmanlık hizmetleri genetik alanındaki gelişmelere paralel olarak giderek artmakta ve yeni alanlara yönelmektedir. Genetik danışmanlık hizmetlerinde meydana gelen bu değişimle birlikte, danışmanlık hizmetleri multidisipliner bir yaklaşımla sunulmalıdır (4). Hemşireler ve ebelerin genetik ile ilgili yeni görevlerini, nitelikli ve etkin bir şekilde, yerine getirebilmeleri için lisans eğitiminden itibaren mesleklerine özgü, genetik ile ilgili eğitim almaları ve gerekli bilgi ile beceriyi kazanmaları şarttır $(4,7)$. Ancak hemşirelik ve ebelik eğitiminde genetik alanında verilen dersler belirli bir standartta yönetilmemekte, çoğunlukla alana özel bir ders olarak verilememekte ve diğer meslek derslerinin içerisinde yer almaktadır (18). Gelişmiş ülkelerde bile okulların yarısından azında genetik ile ilgili mesleki konulara özgü müfredat bulunmayabilmektedir (7). Sonuçta ise bu okullardan genetik danışmanlık alanında yeterli eğitim alamadan ebe ve hemşireler mezun olabilmektedir. Çalışmada öğrencilerin küçük bir kısmı lisans döneminde aldıkları genetik eğitimi yeterli bulduğunu belirtmiştir. Literatür de mezuniyet öncesi ya da sonrası hemşirelerin genetik konusunda kendilerini yeterli görme oranlarının ve bilgi düzeylerinin düşük olduğu görülmektedir (9). Yapılan bir çalışmada hemşirelerin \%20 'si genetik dersi almadığını ve sadece $\% 6,7$ 'si mesleğe özgü genetik dersi aldığını ifade etmiştir (18). Ülkemizde yapılan bir çalışmada hemşirelerin \%82'si mesleki eğitimlerinde genetik konusuyla ilgili ders almadıklarını, genetik bilgisini çeşitli derslerin içerisinde aldıklarını ve \%20'si alınan dersin hasta ve yakınlarına genetik danışmanlık yapabilecek kadar yeterli bulduğunu ifade etmiştir (13). Sonuçlar doğrultusunda genetik alanında çeşitli derslerin lisans eğitiminde yer almasına ihtiyaç olduğu düşünülmektedir.

Çalışmada genetik danışmanlık sürecinde hemşire ve ebelerin rol ve sorumlulukları hakkında öğrenci görüşleri ele alındı. Öğrencilerin yarıdan fazlası hemşirenin, yarıya yakını ise ebenin bu süreçte aktif rol alması gerektiğini ifade etti. Genetik teste bireyi hazırlama, bireyin geçmiş sağlık 
öyküsünü alma, genetik testlerden önce aileye gerekli konularda danışmanlık yapma ve aileye psikolojik destek sağlama çoğunlukla hemşirenin rol ve sorumlulukları arasında ifade edildi. Öğrenciler, ebenin rol ve sorumluluklarını hemşireye göre daha düşük oranlarda bildirirken; "aileye psikolojik destek sağlama, genetik test ve danışmanlık sürecinin sosyal etkileri ile ilgilenme, soy ağacı çizme, genetik test sırasında birey ve aileye gerekli danışmanlığı yapma" ebelerin rol ve sorumlulukları arasında en fazla ifade edilenlerdi. Genetik test sonuçları ile ilgilenme ve genetik alanında uzmanlaşma ise her iki meslek grubu içinde en az ifade edilen mesleki rol ve sorumluluklar arasındaydı. Verilerin toplanması, raporlanması ve sunumu aşamalarında sadece başvuran bireyin sağlık öyküsünün önemsenmesi ve aile öyküsünün önemsenmemesi, iş yükü fazlalığı, sağlık personelinin bu durumu rol ve sorumlulukları içerisinde görmemesi gibi durumlar ebe ve hemşirenin genetik danışmanlık sürecinde aktif rol almamasına yol açmaktadır. Bir çalışmada ebe ve hemşirelerin genetik danışmanlık sürecinde önemli olan genetik tanılama, prenatal tanı testleri, genetik bozukluğun sonuçları gibi konularda danışmanlık yapmanın kendi görevleri olmadığını ifade ettiği bulunmuştur (16). Ayrıca genetik danışmanlık sürecinde yeterli mesleki bilgi ve beceriye sahip olmama ya da olmadığına inanma da bu süreci olumsuz etkilemektedir. Çalışmalarda ebe ve hemşirelerin büyük çoğunluğunun genetik danışmanlık sürecinde bilinmesi gereken temel bilgileri bilmediği bildirilmiştir (15-18). Öğrencilerin genetik danışmanlık sürecinde mesleki rol ve sorumlulukları konusunda sınırlı ifadelerin olmasının kendilerini bu alanda yeterli görmemelerinin bir sonucu olabilir. Ebe ve hemşireler, genetik danışmanlığa başvuran birey ile etkili iletişime geçme, hasta ve aile hikâyesi alabilme, düzenli ve sistemli kayıt tutabilme ve bazı hastalıklar için risk faktörlerini belirleyebilme süreçlerinde gerekli bilgi ve beceriye sahiptirler (7). Bu doğrultuda rol ve sorumlulukları şekillenmelidir $(17,19)$.

Çalışmada genetik hastalık ve danışmanlık sürecinin bireyin sosyal yaşamına etkileri hakkında öğrenci görüşleri ele alındı. Öğrenciler sürecin en çok "bireyin aile içindeki rol ve sorumluluklarını, çocuk sahibi olma kararlarını ve geleceğe yönelik planlarını etkileyeceğini ifade etti. Literatürde genetik danışmanlık sürecinde ortaya çıkan ve bireyi psikolojik, yasal, etik gibi birçok alanda etkileyen durumlar bildirilmektedir $(10,20)$. Bireylerin aile ilişkilerinde bozulma, ayrımcılık, etiketlenme, işten çıkarılma, sağlık sigorta şirketlerinin genetik olarak hasta olma olasılığı yüksek olan bireylere hizmet vermek istememeleri gibi birçok şekilde bireyler sosyal olarak olumsuz etkilenmektedir. Bu nedenle, bu sürecin bireylere olan etkileri genetik danışmanlıkta ele alınmalıdır.
Çalışmada genetik test sonuçları hakkında başvuru yapan birey, doktor, hemşire, ebe ve birinci derece yakınına en yüksek oranda, işveren ve okula ise düşük oranda bilgi verilmesi gerektiği belirlenmiştir. Genetik testlerin sonuçlarının bildirilmesinde birey, aile ve sağlık çalışanları açısından çok yönlü sonuçların olabileceği unutulmamalıdır (14). Bu sürecin etik, yasal, ekonomik, sosyal ve psikolojik yansımaları göz önünde tutulmalıdır. Ayrıca toplumsal ve kültürel değerleri de içeren bütüncül yaklaşım sergilenmelidir.

\section{Sonuç ve öneriler}

Çalışmada hemşirelik ve ebelik öğrencilerinin genetik alanında aldıkları mesleki eğitimi çoğunlukla yetersiz bulduğu, genetik danışmanlık sürecinde sosyal destek ve danışmanlık ile ilgili rol ve sorumlulukları hemşire ve ebelere daha yüksek oranda yükledikleri, alana özgü bilgi ve beceri gerektiren mesleki rol ve sorumlulukları ise daha az oranda benimsedikleri bulunmuştur. Genetik danışmanlık sürecinde ebe ve hemşirelerin eğitim düzeylerindeki yetersizlikler, mesleki hayatlarında alana özgü daha az sorumluluk almalarına yol açabileceği düşünülmektedir. Genetik alanında daha kapsamlı ve iyi bir eğitimle, genetik danışmanlık sürecinde öğrenciler kendilerine daha fazla oranda güvenebilecek, bütüncül ve güvenli bakım hizmetini bireylere sunabilecektir. Dolayısıyla olası olumsuzlukların önlenmesi ve bakım kalitesinin yükseltilmesi için genetik konusunun lisans eğitimi müfredatında yer alması, mesleki eğitim içeriğinin güncel yaklaşımlar doğrultusunda yeniden değerlendirilmesi ve var olan boşlukların giderilmesi önerilmektedir.

Çalışmada genetik hastalıkların sosyal etkileri hakkında öğrenci görüşleri ele alındığında, öğrencilerin genetik hastalıkların etkileri ile ilgili farkındalık düzeylerinin olduğu düşünülmektedir. Ancak test sonuçları hakkında birey, ailesi, sağlık personeli ve diğer kurum ve kuruluşlara bilgi verilebileceği yönünde öğrenci görüşleri, genetik alanına özgü etik, yasal, sosyokültürel durumların da öğrenciler ile irdelenmesi gerektiğini akla getirmektedir.

Araştırmamızda elde edilen bulgular tanımlayıcı olarak kalmakta olup konunun daha geniş örneklemde, mesleki rol ve sorumlulukların, genetik bilginin, yasal, etik ve sosyal konularında incelendiği çalışma tasarımlarında ele alınması önerilmektedir.

\section{Teşekkür Yazısı}

Bu çalışmanın hazırlanmasında vermiş olduğu değerli katkılardan dolayı Prof. Dr. Belgin Akın'a ve bu çalışmaya katılan hemşirelik ve ebelik öğrencilerine teşekkür ederiz. 


\section{Kaynaklar}

1. Durmaz B, Alpman Durmaz A, Özkınay F, Çoğulu Ö. Genetik danışmanlık ve önemi. CMJ 2011; 33: 259-65.

2. Uluşahin A, Kara Özer S, Akarsu N, Aydın E. Psikiyatrik genetik hastalarında bilgilendirilmiş olur. Türk Psikiyatri Dergisi 2001;12:53-9.

3. Godino L, Turchetti D, Skirton H. Genetic counseling: a survey to explore knowledge and attitudes of Italian nurses and midwives. Nurs Health Sci 2013; 15: 15-21. [CrossRef]

4. Arimori N, Nakagomi S, Mizoguchi M, Morita M, Ando H, Mori A, et al. Competencies of genetic nursing practise in Japan: A comparison between basic and advanced levels. JJNS 2007; 4: 45-55. [CrossRef]

5. Barr O, McConkey R. Health visitors' perceived priority needs in relation to their genetics education. Nurse Educ Today 2007;27:293302. [CrossRef]

6. Mattick JS, Dziadek MA, Terrill BN, Kaplan W, Spigelman AD, Bowling FG, et al. The impact of genomics on the future of medicine and health. Med J Aust 2014; 201: 17-20.

7. Thompson HJ, Brooks MV. Genetics and genomics in nursing: Evaluating Essentials implementation. Nurse Educ Today 2011;31:623-7. [CrossRef]

8. Barnoy S, Levy O, Bar-Tal Y. Nurse or physician: whose recommendation influences the decision to take genetic tests more? J Adv Nurs 2010; 66: 806-13. [CrossRef]

9. Godino L, Skirton H. A systematic review of nurses' knowledge of genetics. J Nurs Educ Pract 2012; 2: 173-84. [CrossRef]

10. Dinç L, Terzioğlu F. The psychological impact of genetic testing on parents. J Clin Nurs. 2006; 15: 45-51. [CrossRef]
11. Lessick M, Anderson L. Genetic discoviries: challenges for nurses who care for children and their families. JSPN 2000;5:47-51.

12. Munroe T, Loerzel V. Assessing nursing students' knowledge of genomic concepts and readiness for use in practice. Nurse Educator 2016; 41: 86-9. [CrossRef]

13. Seven M, Akyuz A, Elbuken B, Skirton H, Ozturk H. Nurses'knowledge and educational needs regarding genetics. Nurse Education Today 2015; 35: 444-9. [CrossRef]

14. Terzioglu F, Dinc L. Nurses' views on their role in genetics. J Obstet Gynecol Neonatal Nurs 2004; 33: 756-64. [CrossRef]

15. Tomatir AG, Çetin Sorkun H, Demirhan H, Akdağ B. Nurses' professed knowledge of genetics and genetic counseling. Tohoku J Exp Med 2006; 210: 321-32.

16. Gharaibeh H, Oweis A, Hamad KH. Nurses' and midwives' knowledge and perceptions of their role in genetic teaching. Int Nurs Rev 2010;57: 435-42. [CrossRef]

17. Skirton $\mathrm{H}, \mathrm{O}^{\prime}$ Connor $A$, Humphreys $A$. Nurses' competence in genetics: a mixed method systematic review. J Adv Nurs 2012;68:2387-98. [CrossRef]

18. Lopes-Junior LC, Carvalho Junior PM, de Faria Ferraz VE, Nascimento LC, Van Riper M, Floria-Santos M. Genetic education, knowledge and experiences between nurses and physicians in primary care in Brazil: A cross-sectional study. Nurs Health Sci 2017; 19: 66-74. [CrossRef]

19. Benjamin C, Birch J, Bradley A, Mannion G. Genetics: examining your competency of practice on a regular basis. Nurs Stand 2013;28:3743. [CrossRef]

20. Swamy AA, Fernandes N. Genetics and its practical applications in nursing. AJMS 2016; 4:194-200. 